\title{
Epidemiology of MS in Russia, a historical review
}

\author{
A. Boyko* , N. Smirnova, S. Petrov and E. Gusev
}

\begin{abstract}
Background: This review summarizes several epidemiological studies of multiple sclerosis (MS) in Russia.

Methods: The Authors selected the most well-organized population-based studies of MS prevalence and incidence in the huge territory of Russia. These studies were mostly published in Russian language and were unknown to international readers.

Results: In the majority of Russian territories MS prevalence ranged from 30 to 70 cases per 100,000 population inhabitants. At most places where the epidemiology of MS had been assessed more than once, an increase in prevalence has been reported over time. Incidence showed fluctuations with an increase in Eastern parts of the country. This increased prevalence despite a relatively stable incidence in the European part of the country may reflect the increased survival of the MS population.
\end{abstract}

Conclusions: Russia as a whole can be considered at medium risk for MS. Significant increase of prevalence rates have been recently reported, especially in Siberia and in the Far East regions of the country.

Keywords: Multiple sclerosis, Epidemiology, Prevalence rates, Russia

\section{Background}

One of the most striking epidemiological characteristics of MS is the distribution of the disease across the world. The traditional view, based on numerous early studies and reviews, is that MS is particularly prevalent in low temperate zones, less common in subtropical zones, and uncommon in tropic zones. Both in the Northern and Southern hemisphere the characteristic pattern have been increasing prevalence towards the poles, although deviations from this pattern can be seen both in Europe and North America as well as in Australia and New Zealand. This distribution suggests an interplay between at least three overlapping factors, a) the genetic makeup of a population; b) geographically determined environmental factors; and c) socioeconomic conditions, including access to medical facilities. Data from the former USSR and late from Russia have never been reported so far in the English literature. In 1960-1970's, the prevalence of MS on the huge territory of the former Soviet Union was reported as at "probably high risk of MS". Ten years later, the famous world distribution

\footnotetext{
* Correspondence: boykoan13@gmail.com

Department of Neurology, Neurosurgery and Medical Genetics of the Prigorov's Russian National Research Medical University and MS Center at Neuroclinica at the Usupov's Hospital, Moscow, Russia
}

MS map by John Kurtzke had no definite information on the majority of regions of the Soviet Union [20]. A first review was performed in 1994 and was mainly based on hospital registers. Although a number of factors may have affected the validity of these first observations, including inconsistencies of diagnostic facilities among different territories [2, 3], bad cases ascertainment, differences in ethnic features, high migration rate and different epidemiological methods. In any case, overall MS prevalence was reported in the low to medium frequency range $[23,26]$.

Since then, the availability of medical service has had a profound impact on the diagnostic accuracy and probability ascertainment, and these factors have improved in most parts of the world and have been more uniform throughout the last three to four decades. After the 1990s, the quality of medical care and the availability of diagnostic methods, including MRI, has become uniform in all Russian territories. A special national program on MS epidemiology was launched in 2002 and new studies, performed according to generally accepted methodologies, provided new information which could be compared with previous studies [5, 6]. The structure and design of these studies were established by a special 
Recommendation of the Russian Ministry of Health Care [11]. Recently the majority of these studies were reviewed [12]. The goal of this publication is to present data on MS prevalence and incidence in Russia, which were published previously only in Russian language.

\section{Materials and methods}

Russia is the largest country in the World. Its territory is 17.1 million of $\mathrm{km}^{2}$ and it accounts approximately for $1 / 8$ of the land mass of the Earth. One third of this country in located in Europe, while $2 / 3$ belongs to Asia. Climate in Russia is quite heterogeneous. For example, in Sochi - Olympic capital of 2014 - average winter temperature is $+5{ }^{\circ} \mathrm{C}$, i.e. a temperate zone; Novosibirsk, the biggest city of Siberia with a population of 1.5 million, shows an average winter temperature of $-15{ }^{\circ} \mathrm{C}$; at the same time in Oimyakon area of Yakutia, known as the "cold pole", the average winter temperature is $-61{ }^{\circ} \mathrm{C}$ : obviously, people cannot live or work in such low temperature. Approximately $20 \%$ of the Russian population resides in the 13 biggest cities: Moscow, St Petersburg, Novosibirsk, Nizhniy Novgorod, Yekaterinburg, Samara, Omsk, Kazan, Chelyabinsk, Rostov-on-Don, Ufa, Volgograd, Perm. The largest cities of Russia are located in the European part of the country - Moscow (11.54 million) and Saint-Petersburg (4.8 million), while more than 10 million are living in the republics of the Northern Caucasus. With 145 million people Russia is the seventh most populated nation in the world. While some $79 \%$ of the residents are Russians, more than 160 ethnic groups live in this huge territory (each of them carrying its own genetic predisposition to MS), including Tatars (20\%), Ukrainians (10\%), Bashkirs (6\%), Chuvash (6\%), Chechen (5\%), Armenians (4\%), and Mordva (3\%). In Russia there are 1147 women per 1000 men [7]. This overrepresentation of women becomes more evident from 33 years of age on. Russia is young country, with a mean population age of 38.8 years in 2010, 36.1 in men and 41.1 in women. The oldest inhabitants are in the Central European area (in the city of Tula mean 42.2 years old, 38.5 for men and 45.2 for women), the youngest in Northern Caucases (in the Ingushetia republic, mean age is 29.6 years old; 28.8 for men and 30.4 for women). Able-bodied population (men 16-59 age and women $16-54$ age) is 89,0 million (61\%), while the remaining is either younger - 26,3 million (18\%) - or elder 29,8 million (21 \%). For Russia, as for most European countries, progressive ageing of inhabitants is increasingly common. According to the national census of 1989, mean age of the population is 34,7 years; 31,9 for man, 37,2 for woman [7]. Since then, mean age of residents has increased by 3 years and reached 37,7 years; 35,2 for man,
40,0 for woman. Literacy in Russia is $99 \%$. There are about 3 million students and 567 institutes of higher education including 48 universities.

The National program on MS epidemiology in Russia was started in 2002. The first step was to establish a network of MS Centers covering the entire country, using as a model the successful Moscow MS Center (established in 1998). The program mostly contemplates two actions: descriptive epidemiology - i.e. analysis of prevalence and incidence using unified methodology of population-based studies and analytical epidemiology case-control studies in different populations analyzing environmental risk factors for MS, case-control pairs matched by age, gender, ethnicity and place of birth. All studies are conducted using a unique methodology that includes the validated questionnaire proposed by the Oslo International Think-tank on MS Epidemiology published in Neurology in 1997 [4].

At present more than 90 studies analyzing MS prevalence and incidence in periods between 1980 and 2013 have been published within this program: they may be compared with some of the best quality studies, done in the 1970-1980 decade. Is several regions (Moscow, Novosibirsk, Blagoveshensk) longitudinal observations for 30 and more years have been done. For this review we have selected data from 68 population-based studies of the best quality from different regions of Russia. These studies used unified design of data collection, evaluation of MS clinical course and methods of statistical analysis.

\section{Results}

The majority of studies used clinical Poser diagnostic criteria while more recent studies, performed after 2005 (7 from 68 to $10.3 \%$ ), used the 2001 McDonald criteria. Generally, MS prevalence varied from 10 to 70 cases per 100,000 population with higher MS frequencies at the West, East and Central parts of the country (Fig. 1). A lower prevalence was recorded in Northern areas and in the Far East of Russia, where a low population density and higher representation of populations of Asian origin including Northern tribes, still less affected by MS, occurs.

Data from some of the studies done in different time periods are presented in the Table and show that there is a general tendency of increasing of MS prevalence almost everywhere in Russia. Explanations for this worldwide occurring phenomenon include: 1) better cases ascertainment because of early diagnosis with a percentage increase of mild cases; 2) free access to DMT, active symptomatic and antibacterial therapy extending the life of MS patients; and 3) no loss of information about these patients because of the general use of MS-registers and electronic data-bases. This improved 


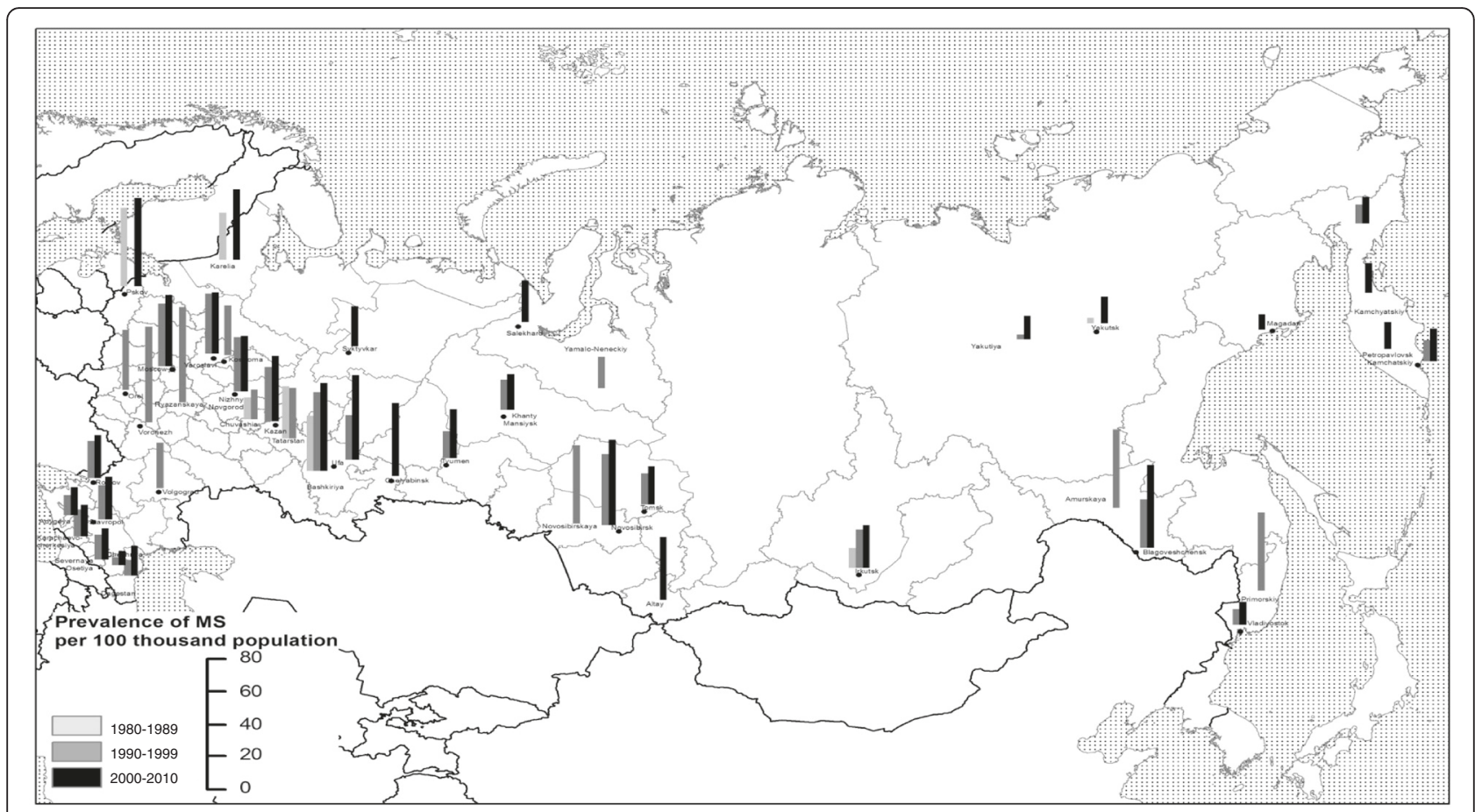

Fig. 1 MS prevalence in different regions of Russia (studied at three time periods: 1980-1990, 1990-2000 and 2000-2010)

management has certainly increased life expectancy and reduced the percent of severely affected MS patients.

The most striking increase of MS prevalence and incidence was noted in Eastern Siberia and in the Far East, where MS frequency increased among third generation of migrants from the European part of Russia. The risk of MS appears to be very homogeneous and varies from 20 to 60 cases per 100,000 population [6] with the majority of populations predominantly Russian, Ukrainian or from other European Caucasoid origin (e.g. Slavonics). Table 1 includes prevalence data from the East to the West of the Russian Federation; Table 2 includes incidence data.

\section{Eastern and Central part of Russia}

The most recent rates of MS prevalence vary from 35 cases per 100,000 in Kostroma up to 67 in Voronezh. Recent MS incidence rates were 2.8 in Yaroslavl and 2.6 in Moscow region, 2.1 in Voronezh, 2.0 in Kostroma and 1.9 in Orel and Nizhniy Novgorod cities [13, 15, 18]. An increase in MS incidence in the Yaroslavl region was seen from 1975 (0.5 per 100,000 population) up to mean 3.0 between 1996 and 2001 (highest rate: 3.1 in 1998) but then decreased to 2.5 between 2001 and 2006 [15]. In the Moscow region, MS incidence was 2.1 between 1995 and 2000 and rose to 2.6 between 2001 and 2006 [6].

\section{Volga river region}

The ethnicity of the population of this area is very different from the Moscow region, with many non-Slavic ethnic groups (Turks) - Tatars, Bashkirs, Chuvashes, as well as the Finno-Ugric group - Mari and Udmurts. MS epidemiological studies in this area showed lower incidence and prevalence rates compared to the Central region of the country with some variation. For example, in Bashkiria the lowest MS prevalence rate reported was 21 per 100,000 population but up to 79 per 100,000 in Northern parts of the republic (the highest in recent studies). Surprisingly, MS prevalence in Ufa, the capital of this republic, was the highest among the Tatars (36.4 per 100,000), intermediate in Russians (near 23 per 100,000), and lowest in Bashkirs (9 per 100,000) [1]. By comparison, at the Moscow region MS is significantly less frequent in Tatars then in Russians. Mean MS incidence in these republics were 2.6 per 100,000 , the highest in the city of Kazan (2.9 per 100,000) [14, 19].

\section{Southern parts of Russia and the Northern Caucasus}

In these areas rates are again lower than in the Central part of Russia, varying from 20 to 35 per 100,000 [30], while in some cities the mean MS incidence was very high: in the past few years it increased up to 9.8 in 20002005 period in the city of Volgograd [8]. In the neighboring Rostov, region the prevalence of MS also varies from district to district with the lowest - 19.5 per 100,000 - in the rural eastern part, and the highest 53.6 per 100,000 - in the northwestern part with industrial enterprises and cities [10]. MS is relatively rare in 
Table 1 MS prevalence in Russia at different time periods

\begin{tabular}{|c|c|c|c|}
\hline Cities/regions & 1980-1989 & 1990-1999 & 200 \\
\hline \multicolumn{4}{|c|}{$\begin{array}{l}\text { Eastern and Central parts of Russia (near } 50 \text { mlns of population, } \\
90 \% \text { Slavonik) }\end{array}$} \\
\hline Karelia & 30 & & 45 \\
\hline Pskov & 55 & & 62 \\
\hline Moscow & & 44 & 55 \\
\hline Orel & & 42 & \\
\hline Yaroslavl & & 42 & 43 \\
\hline Kostroma & & 35 & \\
\hline Voronezh & & 67 & \\
\hline Nizhniy Novgorod & & 38 & 39 \\
\hline Ryazan & & 61 & \\
\hline \multicolumn{4}{|c|}{$\begin{array}{l}\text { Volga-river regions (near } 30 \mathrm{mlns} \text { of population, } 40 \% \text { Slavonik, } \\
50 \% \text { Turks, } 10 \% \text { others) }\end{array}$} \\
\hline Republic of Tatarstan & & 32 & 33 \\
\hline Kazan (capital of Tatarstan) & & 38 & 46 \\
\hline Republic of Bashkiria & 35 & 50 & 56 \\
\hline Northern parts of Bashkiria & & 79 & \\
\hline Ufa (capital of Bashkiria) & & 31 & 59 \\
\hline Republic of Chuvashia & 14 & 19 & \\
\hline
\end{tabular}

Southern parts of Russia and the Northern Caucuses (near 30 mlns of population, $40 \%$ Slavonik, $60 \%$ others - ethnic groups of the Northern Caucuses)

$\begin{array}{lll}\text { Stavropol } & 24 & 30 \\ \text { Rostov-na-Dony } & 26 & 30 \\ \text { Volgograd } & 32 & \\ \text { Republic of Karachaero-Cherkessia } & 17 & 20 \\ \text { Republic of Dagestan } & 10 & 19 \\ \text { Republic of Adigea } & 13 & 18 \\ \text { Republic of Northern Osetia } & 16 & 20 \\ \text { Republic of Chechnya } & 5 & 9\end{array}$

Ural region and the Western Siberia (near $10 \mathrm{mlns}$ of population, $70 \%$ Slavonik, $30 \%$ others)

$\begin{array}{lll}\text { Tyumen } & 19 & 34 \\ \text { Chanti-Mansiysk region } & 21 & 25 \\ \text { Yamalo-Nentskyi region } & 20 & \\ \text { Salechadr } & & 29 \\ \text { Tomsk } & 22 & 27 \\ \text { Siktivkar } & & 28 \\ \text { Cheliabinsks } & & 51 \\ \text { Novosibirsk } & 50 & 60\end{array}$

The Eastern Siberia and the Far East (near $5 \mathrm{mlns}$ of population, $80 \%$ Slavonik, $20 \%$ others)

$\begin{array}{llll}\text { Irkutsk } & 14 & 27 & 30 \\ \text { Blagoveshensks } & & 34 & 58 \\ \text { Amur region } & & 50 & \\ \text { Yakutsk } & 4 & & 19\end{array}$

Table 1 MS prevalence in Russia at different time periods (Continued)

\begin{tabular}{lcc}
\hline Altay region & 10 & 17 \\
The Primorsk region & 11 & 16 \\
Vladivostok & 19 \\
The Northern part of Sakhalin & 12 & 17 \\
The Southern part of Sakhalin & 15 & 23 \\
The Northern part of Kamchatka & 11 \\
The Southern part of Kamchatka & & 17 \\
Magadan &
\end{tabular}

the republics of the Northern Caucuses with MS prevalence less than 20 at majority of sites (Table 1).

\section{Ural region and the Western Siberia}

Several population-based studies were recently completed in the Tyumen region and in the city of Novosibirsk. The Tyumen region is divided in three parts: the Northern Yamal region, scarcely populated, where $6.8 \%$ of the population descends from the Northern tribes (Nentsi, Mansy, Khanti and others) and shows a medium level MS prevalence - 27.8 per 100,000 [27, 28]. Conversely, the KhantiMansi region, consistently more populated and with only

Table 2 Some recent MS incidence rates in Russia (according to latest published data)

\begin{tabular}{ll}
\hline Cities & MS incidence \\
\hline Eastern and Central parts of Russia & \\
Moscow & 2.6 \\
Orel & 1.9 \\
Yaroslavl & 2.8 \\
Voronezh & 2.1 \\
Nizhniy Novgorod & 1.9 \\
Volga-river regions & \\
Kazan & 2.9 \\
Ufa & 2.0
\end{tabular}

Southern parts of Russia and the Northern Caucuses

Stavropol $\quad 1.8$

Rostov-na-Dony $\quad 1.5$

\begin{tabular}{ll} 
Volgograd $\quad 9.8$ \\
\hline
\end{tabular}

Ural region and the Western Siberia

Tyumen 1.8

Tomsk 2.1

Novosibirsk $\quad 3.5$

The Eastern Siberia and the Far East

Irkutsk 1.6

Blagoveshensks $\quad 2.1$

Yakutsk 1.2 
$1.5 \%$ of the population coming from the Northern tribes has an MS prevalence of only 14.3 per 100,000. The highest prevalence, close to 40.5 per 100,000, was found in the Southern part of the region with mostly populated by Russians and hosting many chemical factories. A very important result of this study was the first recorded cases of definite MS in the Northern tribes - overall the prevalence in this area was 2.8 per 100,000 population (highest in Komi-Ziriane ethnic group - up to 16 per 100,000) [29].

A retrospective study covering 25 years in Novosibirsk demonstrated a significant increase in MS incidence in this territory between 1980 and 2000 that rose from 1.6 up to 5.4 cases per 100,000 [21]. Current incidence in this area has stabilized between 2.5 and 3.5 cases per 100,000 population. MS prevalence here in one the highest in the entire Siberia region - near 60 cases per 100,000 population [22].

\section{The Eastern Siberia and the Far East}

A population-based study was performed in Yakutia. Previous studies in this area were completed in the 1980's, apparently based mainly on hospital cases. MS prevalence (2.1 per 100,000) and incidence (0,2 per 100,000) were reported to be extremely low. The first MRI scanner in this region started to work in 1993. The first clinically definite MS case according to Poser criteria in native Yakuts was reported only in 1995, with the first autopsy confirmed MS case obtained in 1998. In the following years native Yakuts withnessed a surge of the disease in their community. More than half young cases were women with numerous lesions at spinal cord at early stages of the disease ("Asian" type of MS). Between 2000 and 2005 the rates in Russians were higher than in Yakuts, but in this ethnic group the prevalence rate was 13.4 per 100,000 in the city and 4.2 per 100,000 in rural regions, while the incidence was 1.8 and 0.4 , respectively. Mean MS prevalence in 2002-2007 was 19 cases per 100,000 [24]. MS incidence at the Amur region varied from 2.8 in $1980-1985$ to 0.3 in $2000-2005$ $[16,17]$. Overall, MS prevalence (1985-2010) varied in this area from 30 to 50 cases per 100,000 [25]. Recent studies of MS prevalence and incidence at the Far East region show relatively low frequencies with MS prevalence from 11 to 23 cases per 100,000 population [9].

\section{Conclusions}

This short review shows that the majority of territories of Russia fall into the medium MS risk zone with a prevalence ranging mostly from 30 to 70 cases per 100,000 population. At most places where the prevalence of MS has been studied on more than once, a definite increase has occurred, similarly to the rest of the Western world [26]. Incidence rates displayed a fluctuating trend, with a clear-cut increase in Eastern parts of the country. This increased prevalence, despite a relatively stable incidence in the European part of the country, may be partially due to an increased survival of the patients as a result of a combination of positive changes. An overall improved medical care, more complete ascertainment procedures and differential emigration of unaffected people [MS was more frequent in Caucasoids Slavoniks then in non-Caucasoid ethnic groups (Turks, Yarutes, etc.)] were all considered as possible contributing factors.

Although an influence of environmental factors must be taken into consideration in determining the sketchy epidemiology if MS in Russia, our data do not allow strong conclusions. The influence of temperature could not be properly assessed because of instability and great variations at the majority of the regions. The increase of MS prevalence in the third generation of the migrants to the Far East suggest a role for ecological and other unknown urban factors. Improvement in diagnosis and/or case ascertainment could certainly lead to a technology-driven increased incidence and prevalence rates, especially in the1980-1990 period. Therefore, the data on increase in incidence of MS across this time period should be interpreted with caution. The correction for delay in ascertainment may be inaccurate to some degree. On the other hand, it is now evident that many territories and ethnic groups from Russia, thought to be free of MS, actually display low and medium levels of MS prevalence.

In conclusion, for this review we have selected population-based, peer-reviewed studies of MS prevalence and incidence in Russia, performed according to modern technology. We are not providing age-standardized, ethnic-specific or sex-specific data, which were not recorded in the majority of the studies. A further analysis and classification of the data presented in Russianspeaking literature along with consistently designed, perspective epidemiological studies are clearly needed to clarify the complex scenario of MS in the Russian confederation.

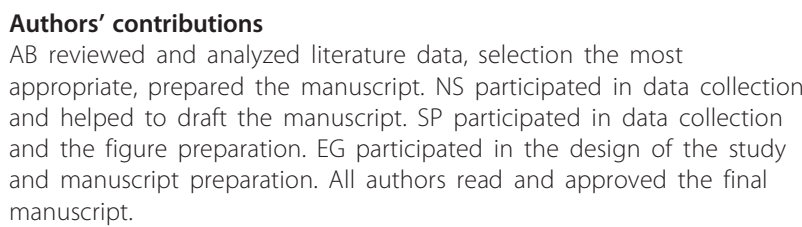

Competing interests

The authors declare that they have no competing interests.

Received: 1 February 2016 Accepted: 5 August 2016

Published online: 12 September 2016

References

1. Bakhtiiarova KZ, Magzhanov RV. Multiple sclerosis in ethnic groups of Bashkortostan Republic. Zh Nevrol Psikhiatr Im S S Korsakova. 2006;3:17-21. (in Russian) 
2. Boyko AN. Multiple sclerosis prevalence in Russia and other countries of the former USSR. In: Firnhaber W, Lauer K, editors. Multiple sclerosis in Europe: an epidemiological update. Alsbach: LTV Press; 1994. p. 219-30.

3. Boyko AN. Epidemiology of multiple sclerosis in Russia and other countries of the former Soviet Union: investigations of environmental and genetic factors. Acta Neurol Scand. 1995:91(Suppl161):71-6.

4. Boyko A. Guidelines for questionnaires to be used in case-control studies of MS. In: The epidemiologic study of exogenous factors in the ethiology of multiple sclerosis. Riise T, Wolfson C (eds.) Neurology. 1997, 49, 2 (Suppl.2) :S75-S80.

5. Boyko A, Zavalishin IA, Spirin NN, et al. Epidemiology of MS in Russia: first data of United Study of Multiple sclerosis epidemiology in Russia. Mult Scler. 2004;10(Supl):157.

6. Boyko AN. Epidemiology of MS in Russia. Mult Scler. 2009;15:S15.

7. Demographic statistics in Russia, Rosstat, 2010. 157p (in Russian).

8. Dokuchaeva NN, Boyko AN. Clinical and epidemiological study of multiple sclerosis in Volgograd city. Zh Nevrol Psikhiatr Im S S Korsakova. 2006;3:4-10. (in Russian).

9. Gavrilenko AA, Evdokimova ZS, Vasilkovskaya GA, Boyko AN. Epidemiology of multiple sclerosis in Primorsky Krai and the Far East regions. Zh Nevrol Psikhiatr Im S S Korsakova. 2012;2:5-8. (in Russian).

10. Goncharova ZA, Balyazin VA. Risk factors of multiple sclerosis development in the population of the Rostov region. Zh Nevrol Psikhiatr Im S S Korsakova. 2009;7:10-5. (in Russian).

11. Gusev El, Boyko AN, Zavalishin IA et al. Epidemiological studies of multiple sclerosis. Methodological recommendations of the Ministry of Health Care of Russian Federation. №2003/82, Moscow; 2003.

12. Gusev El, Zavalishin IA, Boyko AN. Multiple sclerosis. Moscow: Guide for neurologists; 2011. (in Russian).

13. Horoshilova NL. Prevalence and risk factors of a multiple sclerosis in the Orel city. Kursk: Thesis on candidate of medical sciences; 2005. (in Russian)

14. Ishmanova SA. Environmental and internal factors defining features of clinic and current of a multiple sclerosis. Kazan: Thesis on candidate of medical sciences; 2003. (in Russian).

15. Kachura DA. Clinical research of a multiple sclerosis on model of a city population of the Yaroslavl area. Ivanovo: Thesis on candidate of medical sciences; 2003. (in Russian).

16. Karnauch $\mathrm{VH}$. Dynamics and clinical presentation of multiple sclerosis in Amur region for the period of 1960 to 2005. Zh Nevrol Psikhiatr Im S S Korsakova. 2009;7:75-8. in Russian.

17. Karnauch VN. Multiple sclerosis in Amur region - 35-year prospective study (epidemiology, clinical course and prognosis). Irkutsk: Thesis on doctor of medical sciences; 2011. (in Russian).

18. Kim ER. The clinical characteristic and epidemiology a multiple sclerosis in the Nizhniy Novgorod area. Nizhniy Novgorod: Thesis on candidate of medical sciences; 2004. (in Russian).

19. Kondratyeva OS. Prevalence and socially-ecomonic features of multiple sclerosis in the Republic of Tatarstan. Kazan: Thesis on candidate of medical sciences; 2003. (in Russian).

20. Kurtzke JF. Epidemiology of multiple sclerosis. In: Koetsier JC, editor. Handbook of clinical neurology, vol.3 (47). Amsterdam: Elsevier; 1985. p. 259-87.

21. Malkova NA. Epidemiology and clinical course of multiple sclerosis (20 years prospective research in Western Siberia). Novosibirsk: Thesis on doctor of medical sciences; 2005. (in Russian).

22. Malkova NA, Shperling LP, Riabukhina OV, Merkulova EA. Multiple sclerosis in Eastern Siberia: a 20-year prospective study in Novosibirsk city. Zh Nevrol Psikhiatr Im S S Korsakova. 2006:3:11-6. (in Russian).

23. Marrie RA. Environmental risk factors in multiple sclerosis aetiology. Lancet Neurol. 2004;3:709-18

24. Minurova AR. Clinical and epidemiological study of multiple sclerosis in Yakutia. Moscow: Thesis on candidate of medical sciences; 2008 (in Russian).

25. Molchanova EE. Risk factors and epidemiology of a multiple sclerosis on model of a city population of the Amur area. Vladivostok: Thesis on candidate of medical sciences; 2002. (in Russian).

26. Pugliatti M, Rosati G. Epidemiology of multiple sclerosis. In: Multiple sclerosis: a comprehensive text. CS Raine, HF McFarland, R Hohlfeld (eds). Elsevier; 2008. p. 126-34.

27. Sivertseva SA. Epidemiological and immunogenetic features of a multiple sclerosis in the Tyumen region. Moscow: Thesis on doctor of medical sciences; 2009. (in Russian).
28. Sivertseva SA, Zhuravlyov MN, Muravyov SA, Boyko AN. Epidemiology of a multiple sclerosis in the Tyumen area. Zh Nevrol Psikhiatr Im S S Korsakova. 2006;3:22-5. (in Russian).

29. Sivertseva SA, Kandala NS, Zhuravlev MN, et al. Multiple sclerosis in the native population of Yamal. Zh Nevrol Psikhiatr Im S S Korsakova. 2010;1:97-9.

30. Trinitatskij JV. Clinical and MRI data in diagnosis and treatment of a multiple sclerosis. Moscow: Thesis on doctor of medical sciences; 2003. (in Russian).

\section{Submit your next manuscript to BioMed Central and we will help you at every step:}

- We accept pre-submission inquiries

- Our selector tool helps you to find the most relevant journal

- We provide round the clock customer support

- Convenient online submission

- Thorough peer review

- Inclusion in PubMed and all major indexing services

- Maximum visibility for your research

Submit your manuscript at www.biomedcentral.com/submit

) Biomed Central 